\title{
Generating hypotheses about care needs of high utilizers: lessons from patient interviews.
}

\author{
Dawn B Mautner \\ Department of Family and Community Medicine, Thomas Jefferson University; Robert Wood Johnson \\ Foundation Clinical Scholars Program, University of Pennsylvania \\ Hauchie Pang \\ Center for Public Health Initiatives, School of Social Policy and Practice, University of Pennsylvania; \\ Department of Family and Community Medicine, Thomas Jefferson University; Herbert Wertheim College \\ of Medicine, Florida International University \\ Jeffrey C Brenner \\ Camden Coalition of Healthcare Providers; Department of Family Medicine, Cooper Medical School of \\ Rolnban thinivanditydditional works at: https://jdc.jefferson.edu/fmfp \\ SidyaAt \&ftare Family Medicine Commons, and the Other Medical Sciences Commons

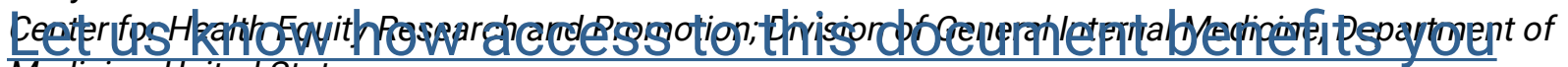 \\ Medicine, United States
}

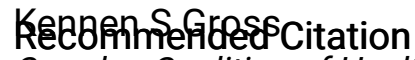

Camden Coalition of Healthcare Providers; Department of Family Medicine, Cooper Medical School of Rowan Uhiversity; Pang, Hauchie; Brenher, Jeffrey C; Shea, Judy A; Gross, Kennen S; Frasso, Rosemary; and Cannuscio, Carolyn C, "Generating hypotheses about care needs of high utilizers: lessons from patient interviews." (2013). Department of Family \& Community Medicine Faculty paperst paperfor3?dditional authors

https://jdc.jefferson.edu/fmfp/43

This Article is brought to you for free and open access by the Jefferson Digital Commons. The Jefferson Digital Commons is a service of Thomas Jefferson University's Center for Teaching and Learning (CTL). The Commons is a showcase for Jefferson books and journals, peer-reviewed scholarly publications, unique historical collections from the University archives, and teaching tools. The Jefferson Digital Commons allows researchers and interested readers anywhere in the world to learn about and keep up to date with Jefferson scholarship. This article has been accepted for inclusion in Department of Family \& Community Medicine Faculty Papers by an authorized administrator of the Jefferson Digital Commons. For more information, please contact: JeffersonDigitalCommons@jefferson.edu. 


\section{Authors}

Dawn B Mautner, Hauchie Pang, Jeffrey C Brenner, Judy A Shea, Kennen S Gross, Rosemary Frasso, and Carolyn C Cannuscio 


\title{
Generating Hypotheses About Care Needs of High Utilizers: Lessons from Patient Interviews
}

\author{
Dawn B. Mautner, MD, MS, ${ }^{1,2, *}$ Hauchie Pang, MPH, ${ }^{3, \star *}$ Jeffrey C. Brenner, MD, ${ }^{4,5}$ Judy A. Shea, PhD, 6,7 \\ Kennen S. Gross, PhD, ${ }^{4,5}$ Rosemary Frasso, PhD, MSc, $\mathrm{CPH}^{3}$ and Carolyn C. Cannuscio, ScD, ScM ${ }^{6,8,9}$
}

\begin{abstract}
Informed by a largely secondary and quantitative literature, efforts to improve care and outcomes for complex patients with high levels of emergency and hospital-based health care utilization have offered mixed results. This qualitative study identifies psychosocial factors and life experiences described by these patients that may be important to their care needs. Semi-structured interviews were conducted with 19 patients of the Camden Coalition of Healthcare Providers' Care Management Team. Investigators coded transcripts using a priori and inductively-derived codes, then identified 3 key themes: (1) Early-life instability and traumas, including parental loss, unstable or violent relationships, and transiency, informed many participants' health and health care experiences; (2) Many "high utilizers" described a history of difficult interactions with health care providers during adulthood; (3) Over half of the participants described the importance to their well-being of positive and "caring" relationships with primary health care providers and the outreach team. Additionally, the transient and vulnerable nature of this complex population posed challenges to follow-up, both for research and care delivery. These themes illuminate potentially important hypotheses to be explored in more generalizable samples using robust and longitudinal methods. Future work should explore the prevalence and impact of adverse childhood experiences among "high utilizers," and the different types of relationships they have with providers. Investigators should test new modes of care delivery that attend to patients' trauma histories. This qualitative study was well suited to provide insight into the life stories of these complex, vulnerable patients, informing research questions for further investigation. (Population Health Management 2013;16:S-26-S-33)
\end{abstract}

\section{Introduction}

$\mathbf{H}$ IGH UTILIZERS OF HEALTH CARE, especially emergency services, have been described as poor, medically complex, and either uninsured or publicly insured. ${ }^{1-3}$ They often suffer concurrently from housing instability, substance use, and mental illness. ${ }^{1,4}$ Literature describing their health and social attributes relies heavily on survey and emergency department (ED) claims data that yield descriptions of comorbidities, insurance information, and demographics. $^{1-3,5-7}$ The patient perspective is rarely represented. ${ }^{4}$
Qualitative methods can provide important insight into the life experiences and psychosocial characteristics of these patients in order to generate hypotheses regarding the antecedents of costly patterns of utilization. Such work can inform the development of more effective interventions.

Nationally, interventions that address complex patient populations with high levels of need (eg, frail, elderly, HIVpositive patients) have demonstrated improvements in health outcomes and costs by assuring comprehensive community-based care and decreasing ED visits, hospitalizations, and readmissions. ${ }^{8,9}$ Similarly, in Camden, New

\footnotetext{
${ }^{1}$ Department of Family Medicine and Community Health and ${ }^{2}$ Robert Wood Johnson Foundation Clinical Scholars Program, University of Pennsylvania, Philadelphia, Pennsylvania.

${ }^{3}$ Center for Public Health Initiatives, School of Social Policy and Practice, University of Pennsylvania, Philadelphia, Pennsylvania.

${ }^{4}$ Camden Coalition of Healthcare Providers, Camden, New Jersey.

${ }^{5}$ Department of Family Medicine, Cooper Medical School of Rowan University, Camden, New Jersey.

${ }^{6}$ Center for Health Equity Research and Promotion at the Philadelphia VA, Philadelphia, Pennsylvania.

${ }^{7}$ Division of General Internal Medicine in the Department of Medicine, ${ }^{8}$ Department of Family Medicine and Community Health, and ${ }^{9}$ Mixed Methods Research Laboratory, Perelman School of Medicine, University of Pennsylvania, Philadelphia, Pennsylvania.

*Current address: Department of Family and Community Medicine, Thomas Jefferson University, Philadelphia, Pennsylvania.

**Current address: Herbert Wertheim College of Medicine at Florida International University, Miami, Florida.

Prior presentation: Robert Wood Johnson Foundation Clinical Scholars Program Annual Meeting, November 2011, Washington, DC.
} 
Jersey, the Camden Coalition of Healthcare Providers' (CCHP's) Care Management Team offered high utilizers of emergency services a comprehensive care management intervention. The Care Management Team provided basic home-based care and assured appropriate follow-up with primary care providers, connection to social services, and support for self-care. ${ }^{10}$ A growing body of evidence shows that focusing on the most complex tier of patients can result in improvements in health outcomes and health care utilization, in some cases decreasing hospital and emergency services utilization and costs. ${ }^{11-15}$

This work was informed by a "social determinants of health" framework, in which life course exposures to adverse conditions and social relationships are understood to shape later life health outcomes - and potentially health care utilization. Mounting evidence demonstrates that adverse childhood experiences (eg, experiencing or witnessing domestic violence, living with substance abuse) predict negative health outcomes throughout the life course, including depressive disorders in adulthood, risky health behaviors (eg, alcohol abuse, illicit drug use, smoking, risky sexual behaviors), and a range of chronic illnesses. ${ }^{16-24}$ This work also was informed by the Behavioral Model for Vulnerable Populations, which posits that, especially in vulnerable patient groups, health care utilization is shaped by predisposing social and demographic factors, access to resources, and health status. ${ }^{25}$

This study was designed to generate hypotheses regarding the health and health care utilization experiences of patients who use high volumes of hospital-based health services. The objectives were (1) to characterize high utilizer patients and their perceptions of their health and health care, and (2) to identify barriers and facilitators to health and health care from these patients' perspectives.

\section{Methods}

This pilot qualitative study employed semi-structured interviews with former patients of the Care Management Team intervention. Shaped by an initial literature review, the interview guide was refined through consultation and piloting with the CCHP, community members, care providers, and experts in fields such as public health, social epidemiology, community-based primary care, and qualitative research. Four domains of interest were identified (Fig. 1): participants' early life experiences; provider relationships, utilization patterns, and health care access; impact of the Care Management Team; and perceived health status. The guide employed open-ended questions and a short sequence of demographic questions.

Using contact information from the Camden Health Database (all Camden hospitals), former patients were recruited to participate beginning in spring 2012. They had been enrolled in the intervention based on observed patterns of high utilization of the ED. Participants were at least 18 years of age, English or Spanish speaking, and competent to consent. Multiple attempts were made to contact all eligible patients who had been seen by the Care Management Team between 2007 and 2012 (Fig. 2).

Follow-up with former patients was challenging for multiple reasons, including transience, housing instability, and severe, complex, advanced mental and physical illness leading to death in several cases. Patients had been discharged from the team up to 4 years prior to the current study. Of the original potential participants, more than half $(n=73)$ were ineligible or unreachable because of subsequent cognitive decline, institutionalization, death, having moved away or other factors, or no longer being connected at the available phone numbers (some numbers originally given by patients were for churches, shelters, or transitional housing facilities). The 19 patients who participated in the study were interviewed in their homes or the facilities in which they reside, or met the team in a private room in a local library, per their choice.

After consent was obtained, interviews were conducted and audio recorded by investigators trained in qualitative interviewing techniques and human subjects protection. Participants received grocery store vouchers (\$20) as an incentive. The study protocol was approved by the Institutional Review Boards of the University of Pennsylvania and the Cooper Health System of Cooper University Hospital.

Recordings were professionally transcribed, deidentified, and checked for accuracy. Beginning with the 4
FIG. 1. Steps from interview guide development through emergence of themes.

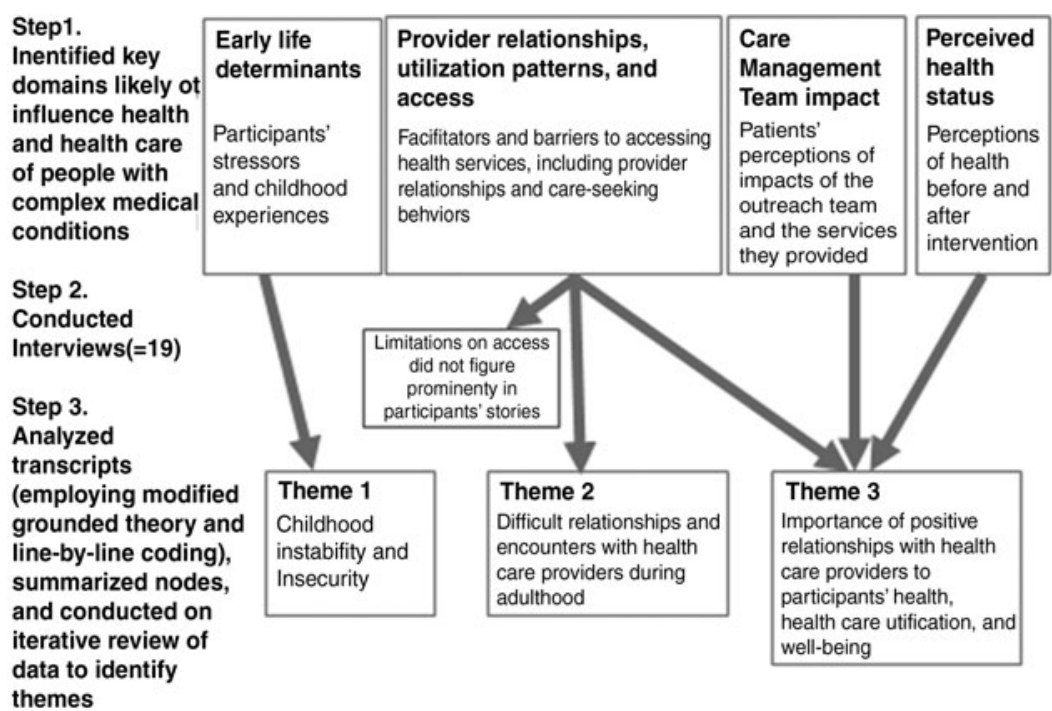




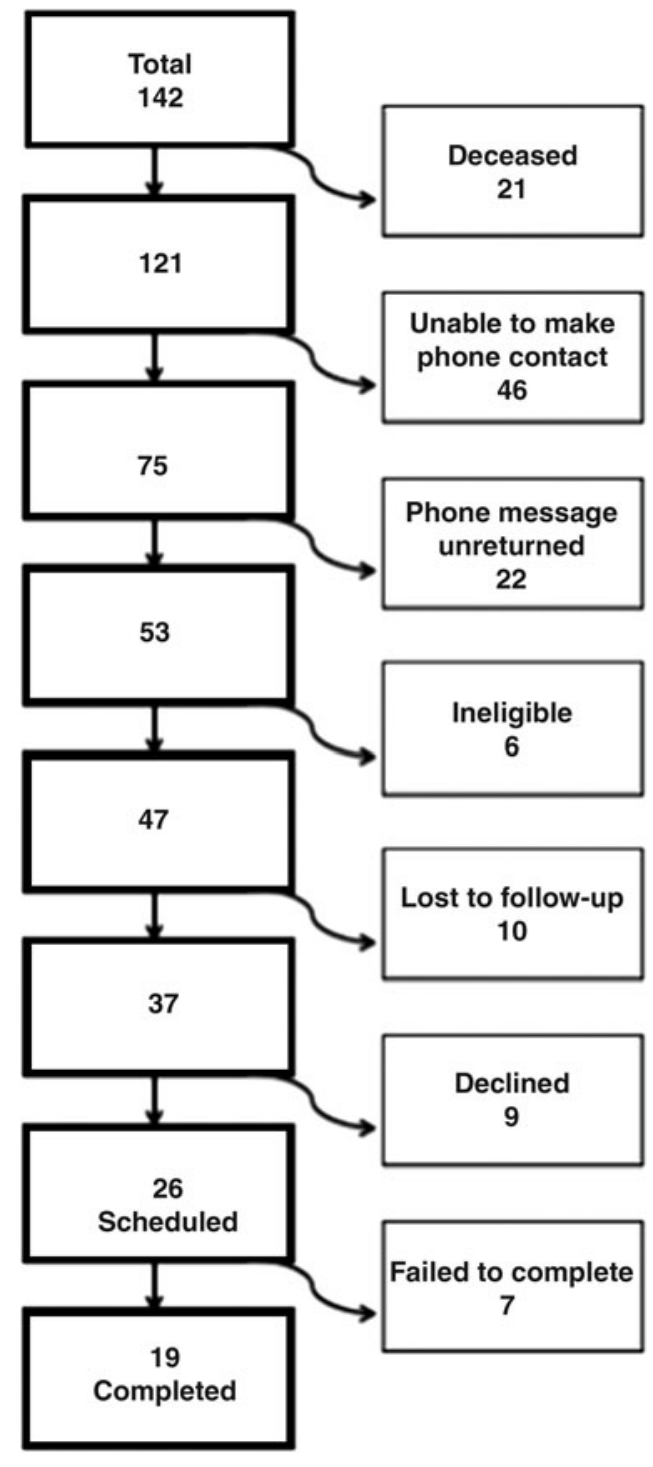

FIG. 2. Recruitment.

original domains specified in the interview guide, a code book was built, which was augmented with additional codes identified through a line-by-line review of transcripts. A modified grounded theory analysis was conducted to determine whether the 4 original domains mapped to issues noted as salient by participants. Two investigators (DM and HP) independently coded transcripts using NVivo 9 , then resolved discrepancies $(\kappa=0.87)$. The team reviewed these data in an iterative process that included memos and conversations to clarify 3 themes revealed by the data (Fig. 1).

\section{Results}

Of the 142 former patients of the Care Management Team, 37 were reached by telephone with up to 10 attempts per patient. Of the 26 who scheduled interviews, 7 potential participants did not present for interviews and were unable to make rescheduled appointments (Fig. 2), and 19 interviews were completed (12 women and 7 men). The mean age was 51.6 years and all spoke English. As
TABle 1. Demographics

\begin{tabular}{|c|c|c|}
\hline & $\mathrm{N}=19$ & Total population (114)* \\
\hline Mean age & 51.6 & 52.2 \\
\hline \multicolumn{3}{|l|}{ Sex } \\
\hline Female & $12(63 \%)$ & $48(41.4 \%)$ \\
\hline Male & 7 (37\%) & $68(58.6 \%)$ \\
\hline \multicolumn{3}{|l|}{ Race } \\
\hline African American & $11(58 \%)$ & $70(46 \%)$ \\
\hline White & $4(21 \%)$ & $9(6 \%)$ \\
\hline Other & $4(21 \%)$ & $72(48 \%)$ \\
\hline \multicolumn{3}{|l|}{ Education } \\
\hline Less than high school & $9(47 \%)$ & - \\
\hline High school graduate & $5(26 \%)$ & - \\
\hline Some college & $4(21 \%)$ & - \\
\hline College graduate & $1(5 \%)$ & - \\
\hline \multicolumn{3}{|l|}{ Employment } \\
\hline Disabled & $12(63 \%)$ & - \\
\hline Unemployed & $3(16 \%)$ & - \\
\hline Working part time & $1(5 \%)$ & - \\
\hline Homemaker & $1(5 \%)$ & - \\
\hline Retired & $2(11 \%)$ & - \\
\hline \multicolumn{3}{|l|}{ Marital status } \\
\hline Single & $5(26 \%)$ & - \\
\hline Married & $5(26 \%)$ & - \\
\hline Widowed & $4(21 \%)$ & - \\
\hline Divorced & $2(11 \%)$ & - \\
\hline Living with a partner & $3(16 \%)$ & - \\
\hline \multicolumn{3}{|l|}{ Income $(N=17)$} \\
\hline$<\$ 14,000$ & $9(47 \%)$ & - \\
\hline$\$ 14,000-\$ 21,000$ & $5(26 \%)$ & - \\
\hline$>\$ 21,000$ & $3(16 \%)$ & - \\
\hline \multicolumn{3}{|l|}{ Insurance } \\
\hline Medicare & $7(37 \%)$ & - \\
\hline Medicaid & $7(37 \%)$ & - \\
\hline Dual Eligible & $4(21 \%)$ & - \\
\hline Private & $1(5 \%)$ & - \\
\hline Uninsured & 0 & - \\
\hline
\end{tabular}

*The total number of patients in the Camden Health Database who were able to be matched to records in the Care Management Team's database was 114 .

shown in Table 1, the sample had more women and more African American participants than white or Hispanic participants.

Three main themes emerged (Fig. 1). First, analysis of multiple codes about individuals' childhood determinants yielded a focus on descriptions of childhood instability. Second, when discussing health care providers and utilization, participants described difficult relationships within the health care system, including negative interactions with providers. Third, in describing their perceived health status, the impact of the Care Management Team, other providers, and their health care utilization, participants noted caring relationships with the Care Management Team and other providers as important to their health and health care decisions.

Most participants explained that they were not struggling with issues of essential health care access at the time of the interviews; they reported having primary care providers, medications, transportation and housing. Diabetes $(n=13)$, depression $(n=7)$, and hypertension $(n=7)$ were the most frequently self-reported medical conditions. 
Table 2. Major Themes with Representative Quotes

Major Theme 1: Instability in childhood $(\mathrm{n}=12)$

\begin{tabular}{l} 
Theme \\
\hline Death of a loved one $\quad(n=5) \quad \begin{array}{l}\text { "I had a little cousin, she actually died from a rare form of cancer when...I } \\
\text { was 8. And she was my best friend, we were together every day...I think } \\
\text { that's when the depression actually started." }\end{array}$
\end{tabular}

Major Theme 2: Difficult relationships with health care providers (not on the Care Management Team) $(\mathrm{n}=12$ )

Theme

Perceived disrespect from and dismissal by non-intervention providers $(n=12)$

Quotation

"This young doctor's...manner of dealing with me was absolutely unbelievable. I felt as though I was being treated as a statistic, because I live in Camden, I'm associated with some lower than average.... As if I'm not even smart enough to think that I have some medical issues, and then when I give her my [highly educated] background, I'm one of

those...There's a lot of biases that a patient has to go through just to get reasonable treatment..."

Major Theme 3: Importance of positive relationships with providers

\begin{tabular}{l} 
Theme Quotation \\
Feeling cared for $(n=10) \quad \begin{array}{c}\text { "They [care management team]...- for the time that they were in my life, } \\
\text { they sort of made me feel like [they were] parents, you know. That's how } \\
\text { much love that they showed me." }\end{array}$ \\
\hline
\end{tabular}

\section{Theme 1: Childhood instability}

A predominance of the participants $(n=12)$ told stories of childhood instability (Table 2). Significant subthemes included early life traumas, such as death of a parent or other loved one, and abusive relationships with primary caregivers throughout childhood. Some described state agencies as their primary caregivers. Transiency was noted, often in the context of escape from abusive relationships $(n=5)$, and often resulted in living on the streets or gang and drug involvement, even as children.

Participant: "I was raised in the streets. I come from a very...dysfunctional family...when I left the house, I was probably 10. Selling drugs. Dealing. Doing all the wrong things. Most of my years were in prison. Juvenile hall and prison so, you know, that's how I grew...I had a very...sad childhood. I was abused and...I was usually mostly by myself trying to survive out there and learning the hard way."

\section{- 38-year-old Hispanic woman with diabetes}

Only 2 individuals specifically described how events in childhood affected their health during adulthood. Nevertheless, many participants related stories of how this instability may have manifested in health issues, especially with regard to mental health. For example, one woman described:

"I had sexual and physical abuse from my parents since I was a baby, since I was 3 or 4...Mother has been very abusive over the years...Every time we went somewhere she was hitting me, punching me, scratched me, and I'd cover it up..."
- 54-year-old white woman with post-traumatic stress disorder, bipolar I disorder, and additional nonpsychiatric chronic conditions

This individual described ongoing difficulty obtaining effective treatment for the post-traumatic stress disorder that repeatedly sent her to the ED. She reported being frequently "suicidal" and "in crisis" as a specific result of childhood abuse, for which she was "in and out of hospitals too much." She reported a shared goal with her therapist of accessing consistent community-based mental health care rather than relying solely on the ED.

Nearly half of the respondents $(n=8)$ named their mother or a mother figure as their most important primary caregiver. The other half referred to a variety of other caregivers, such as grandparents, other relatives, or the state, or they declined to answer; these situations were described by some participants as traumatic, and by others as a normal course of events.

Of participants who described instability in childhood, half noted familial estrangement in adulthood $(n=6)$. When asked if there was someone they could depend on now for help, most participants spoke of having only 1 or 2 individuals that they could rely on, if any, suggesting a lack of social support in adulthood for nearly all of these respondents.

\section{Theme 2: Difficult relationships and encounters with health care providers during adulthood}

Participants described difficult encounters with health care providers (not on the Care Management Team) (Table $2)$. More than half of participants $(n=12)$ related stories of 
encounters that had upset them; several explicitly mentioned withdrawing from outpatient providers by choosing not to attend appointments with those providers as a result. Over a third of participants switched providers because of dissatisfaction with those relationships. Others who had not switched chose not to follow a given provider's instructions as a result of these negative interactions. Most of the stories of negative health care encounters focused on feeling disrespect from providers, while others specifically described feeling discriminated against by providers because of race or sex.

"I had a doctor treat me in the ER. I was having chest pains. And I was told I was a drug addict and it was in my head. And a week later I had a massive heart attack. I also explained to him that every young black person that walks in the hospital is not seeking drugs. That some of us do actually have problems. We may not know what they are, but they're real. And every female doesn't imagine she's sick."

- 49-year-old African American woman with hypertension, asthma, congestive heart failure, status post myocardial infarction

When answering questions about trusting their health care providers, almost half $(n=9)$ of participants stated that they distrusted a particular (usually hospital-based) provider. Respondents generally expressed trust in their primary care providers.

\section{Theme 3: Importance of positive relationships with health care providers}

Half of participants indicated the importance of "feeling cared for" by providers $(n=10)$. This theme recurred throughout the interviews, especially during descriptions of the Care Management Team. When asked about the best part of the intervention, rather than describing specific services, most participants described the importance of the emotionally supportive interactions they experienced. These participants reported that the experience of feeling cared for was a motivation to improve their own health behaviors $(n=10)$ (Table 2).

Diabetes, depression, and hypertension were the most commonly reported conditions. Despite the natural history of these complex chronic diseases and their tendency to reflect a pattern of deterioration over time, 7 participants reported improvements in their own perceived health status after the intervention. Five of those participants specifically attributed this improvement to the intervention.

"They make you feel like you're not alone, and they understand you and the things you're going through. And they actually help explain why you're going through these things...you don't feel like just a patient."

- 24-year-old African American woman with depression and Type 1 diabetes

These participants articulated an appreciation for continuity in relationships with providers, including members of the Care Management Team. A majority of respondents $(n=14)$ described their preference for office-based primary care with their usual providers, reserving the ED for emergent medical necessity or after-hours needs.

\section{Discussion}

The 3 main themes elucidated reflect instability throughout the life course. Childhood instability, including traumas, abusive relationships, parental loss, and transiency, characterized the majority of the participants. Most reported some difficulty with provider relationships and, often, how that impacted their health care seeking behaviors. Finally, the participants reported that "caring" providers were particularly important in the trajectories of their illnesses and lives, emphasizing the compassion of the Care Management Team. Providers from the intervention were described as dependable, sensitive, and thoughtful, suggesting that these traits in providers may resonate for individuals whose childhoods lacked caregivers with these qualities.

Findings from this study corroborated existing evidence in a variety of ways. For example, many participants described childhood instability, including experiences in parallel with the Adverse Childhood Experiences Study. ${ }^{19}$ Participants who reported exposure to adverse childhood experiences also suffered from outcomes described in the literature, including homelessness, risky health behaviors, and depression. ${ }^{16-24}$ Attachment theory provides a powerful framework for understanding these data, suggesting that insecure attachment during infancy results in disrupted patterns of attachment in adult relationships, ${ }^{26-28}$ such as those between these patients and their health care providers beyond the Care Management Team. Newer longitudinal prospective data suggest that physical illness also may be predicted by poor attachment during infancy. ${ }^{29}$ Few studies have examined later-life health care utilization patterns among people who experienced early traumas, which may be a fruitful area for further inquiry in a variety of settings and with longitudinal study designs.

Evidence shows that a lower quality of care often is provided to minority or low socioeconomic status (SES) patients. ${ }^{30-32}$ Several participants in this study expressed that they felt that their care sometimes was compromised by perceived disrespect from health care providers, citing race-, sex- or SES-based discrimination. Prior studies have noted that patients may respond to this sense of disrespect or distrust from providers with decreased adherence to medication regimens, refusal of services, or delays in care. ${ }^{30,33}$ The perception of disrespect perpetuates a cycle of difficult relationships between patients and providers that may adversely affect health or health care utilization. Conversely, participants emphasized the importance of caring, trusting, and longitudinal relationships with providers, both on the Care Management Team and with primary care providers. Comorbid mental illness, especially depression, makes managing chronic illnesses such as diabetes more challenging. ${ }^{34-37}$ Consistent, positive relationships with primary care providers have been shown to decrease rates of hospitalization and ED use for complex patients who struggle with a combination of multiple chronic illnesses, mental illness, and psychosocial challenges. ${ }^{38-42}$

Limitations of this study include selection bias and a small sample size. Patients who had a positive experience with the 
intervention may have been more likely to respond to investigators than those who did not participate initially or had a negative experience. Furthermore, the sickest or most transient patients of the intervention may have been less likely to participate. Because recruitment was done by telephone, those who enrolled in this study likely were among the more stable and accessible in this population; thus, those struggling with housing instability who have been noted as high utilizers ${ }^{4}$ were not well represented. To gain consensus in identifying key themes, data were reviewed by multiple investigators and brought back to the panel of experts to help decrease potential investigator biases.

While CCHP continues its work, the outreach intervention has changed considerably, as have the eligibility criteria for enrollment of patients. Finding and connecting with patients as complex and vulnerable as these in communities like Camden is a known challenge to those in the field. The challenges faced in recruiting participants mirrors challenges faced by the Care Management Team in delivering (free) care to patients longitudinally. The team expends significant resources working to connect with patients over time via repeated telephone and spontaneous home visits. The prevalence of these themes may be the same in a non-high-utilizer sample, particularly in Camden; this sample was intended to capture the range of experiences of patients in the program, rather than to be representative of all high utilizers. Additionally, the study was not designed to examine causal influences on care-seeking behaviors.

Care Management team members, primary care providers, and hospital-based providers all struggle with the combination of medical, psychosocial, financial, and interpersonal problems these patients bring into the exam room. In one survey, 95\% of physicians serving lowincome, urban communities agreed that social needs were as important as medical needs, $85 \%$ expressed the desire to write prescriptions for social needs such as housing or transportation, and $80 \%$ of physician respondents were not confident in their ability to manage their patients' social needs. ${ }^{43}$

Screening for a history of childhood instability at the time of admission or discharge from the hospital, a transitional care program, ${ }^{44}$ or a care management intervention such as the Care Management Team would inform development of health care interventions. The Sanctuary Model ${ }^{45}$ references many of the narratives observed in this study's population and provides a trauma-informed framework for building a productive, positive therapeutic alliance. These narratives discuss how coping mechanisms that helped patients survive childhood instability may have become maladaptive in adulthood; how childhood abuse leads to disrupted attachment behavior and impaired capacity to form stable relationships; and how depressive symptoms, learned helplessness, low self-esteem, and hopelessness may present with secondary symptoms that the patient does not connect to the original traumas and that can be difficult to diagnose and treat. For these children, the health care system may represent a place of safety. As they grow up, they may be driven back to using the health care system as a place of sanctuary, representing a pathway to higher-than-normal utilization of health care for people who experienced an unstable childhood.
Our health care system is not designed to address this broad array of needs, and the result is the costly revolving door phenomenon of high utilization of hospital-based services. The study participants were selected for their patterns of utilization; the perspectives they offer give insight into how the health care system has failed them. These data highlight the influence of psychosocial factors, such as childhood instability, on the lives of the participants. Future directions should include investigation of the hypotheses that: (1) adverse childhood experiences may predict costly future patterns of health care utilization; (2) earlier life trauma influences relationships with health care providers and the health care system, potentially via challenges to attachment; and (3) trauma-informed health care delivery may improve outcomes for complex patients. Robust longitudinal methods using generalizable samples will be necessary to answer these questions. Ultimately, nuanced understanding of these individuals' complex psychosocial as well as medical needs may need to be integrated into health care delivery in order to optimize patient-centered models of care and outcomes.

$$
\begin{aligned}
& \text { "It is easier to build strong children than to repair broken } \\
& \text { men." }
\end{aligned}
$$$$
\text { -Frederick Douglass }
$$

\section{Acknowledgments}

The authors appreciate the sponsorship of the Robert Wood Johnson Health and Society Scholars Program Fund at the University of Pennsylvania. We wish to acknowledge the support of Katrina Armstrong, MD, MSCE and Glenda Wrenn, MD, MA throughout the process of developing this project. Finally, we wish to thank the Robert Wood Johnson Foundation Clinical Scholars Program at the University of Pennsylvania for the postdoctoral training support of Dr. Mautner, during which this work was completed. Parts of this work have been presented at the Robert Wood Johnson Clinical Scholars' National Meeting in November 2011.

\section{Author Disclosure Statement}

Drs. Mautner, Brenner, Shea, Gross, Frasso, and Cannuscio, and Ms. Pang declared no conflicts of interest with respect to the research, authorship, and/or publication of this article. The authors received the following financial support for the research, authorship, and/or publication of this article: Robert Wood Johnson Health and Society Scholars Program Fund at the University of Pennsylvania; Robert Wood Johnson Foundation Clinical Scholars Program at the University of Pennsylvania.

\section{References}

1. Hunt KA, Weber EJ, Showstack JA, Colby DC, Callaham ML. Characteristics of frequent users of emergency departments. Ann Emerg Med 2006;48:1-8.

2. Cook LJ, Knight S, Junkins EP Jr, Mann NC, Dean JM, Olson LM. Repeat patients to the emergency department in a statewide database. Acad Emerg Med 2004;11:256-263.

3. Zuckerman S, Shen Y. Characteristics of occasional and frequent emergency department users: Do insurance coverage and access to care matter? Med Care. 2004;42:176-182. 
4. Raven MC, Billings JC, Goldfrank LR, Manheimer ED, Gourevitch MN. Medicaid patients at high risk for frequent hospital admission: Real-time identification and remediable risks. Urban Health 2009;86:230-241.

5. Weber EJ, Showstack JA, Hunt KA, Colby DC, Callaham ML. Does lack of a usual source of care or health insurance increase the likelihood of an emergency department visit? Results of a national population-based study. Ann Emerg Med 2005;45:4-12.

6. Fuda KK, Immekus R. Frequent users of Massachusetts emergency departments: A statewide analysis. Ann Emerg Med 2006;48:9-16.

7. Kne T, Young R, Spillane L. Frequent ED users: Patterns of use over time. Am J Emerg Med 1998;16:648.

8. Fretwell MD, Old JS. The PACE program: Home-based care for nursing home-eligible individuals. NC Med J 2011;72: 209-211.

9. Furin JJ, Behforouz HL, Shin SS, et al. Expanding global HIV treatment: Case studies from the field. Ann NY Acad Sci 2008;1136:12-20.

10. Green SR, Singh V, O’Byrne W. Hope for New Jersey's city hospitals: The Camden initiative. Perspect Health Info Manag 2010;7:1d

11. Okin RL, Boccellari A, Azocar F, et al. The effects of clinical case management on hospital service use among ED frequent users. Am J Emerg Med 2000;18:603-608.

12. Linkins KW, Brya JJ, Chandler DW. Frequent users of health services initiative: Final evaluation report. Available at: http://www.chcf.org/ /media/MEDIA\%20LIBRARY\% 20Files/PDF/F/PDF\%20FUHSIEvaluationReport.pdf. Accessed May 1, 2012.

13. Sadowski LS, Kee RA, Vanderweele TJ, Buchanan D. Effect of a housing and case management program on emergency department visits and hospitalizations among chronically ill homeless adults: A randomized trial. JAMA 2009;301:17711778.

14. Larimer ME, Malone DK, Garner MD, et al. Health care and public service use and costs before and after provision of housing for chronically homeless persons with severe alcohol problems. JAMA 2009;301:1349-1357.

15. Kessell ER, Bhatia R, Bamberger JD, Kushel MB. Public health care utilization in a cohort of homeless adult applicants to a supportive housing program. Urban Health 2006;83:860-873.

16. Chapman DP, Whitfield CL, Felitti VJ, Dube SR, Edwards VJ, Anda RF. Adverse childhood experiences and the risk of depressive disorders in adulthood. J Affective Disord 2004;82: 217-225.

17. Dube SR, Felitti VJ, Dong M, Chapman DP, Giles WH, Anda RF. Childhood abuse, neglect, and household dysfunction and the risk of illicit drug use: the adverse childhood experiences study. Pediatrics 2003;111:564-572.

18. Hillis SD, Anda RF, Felitti VJ, Nordenberg D, Marchbanks PA. Adverse childhood experiences and sexually transmitted diseases in men and women: A retrospective study. Pediatrics 2000;106:E11.

19. Felitti VJ, Anda RF, Nordenberg D, et al. Relationship of childhood abuse and household dysfunction to many of the leading causes of death in adults: The adverse childhood experiences (ACE) study. Am J Prev Med 1998;14: 245-258

20. Dube SR, Anda RF, Felitti VJ, Edwards VJ, Croft JB. Adverse childhood experiences and personal alcohol abuse as an adult. Addict Behav 2002;27:713-725.
21. Herman DB, Susser ES, Struening EL, Link BL. Adverse childhood experiences: Are they risk factors for adult homelessness? Am J Public Health 1997;87:249-255.

22. Whitfield CL, Anda RF, Dube SR, Felitti VJ. Violent childhood experiences and the risk of intimate partner violence in adults: Assessment in a large health maintenance organization. J Interpers Violence 2003;18:166-185.

23. Dube SR, Anda RF, Felitti VJ, Chapman DP, Williamson DF, Giles WH. Childhood abuse, household dysfunction, and the risk of attempted suicide throughout the life span: findings from the adverse childhood experiences study. JAMA 2001;286:3089-3096.

24. Anda RF, Croft JB, Felitti VJ, et al. Adverse childhood experiences and smoking during adolescence and adulthood. JAMA 1999;282:1652-1658.

25. Gelberg L, Andersen RM, Leake BD. The behavioral model for vulnerable populations: Application to medical care use and outcomes for homeless people. Health Serv Res 2000;34: 1273-1302.

26. Bretherton I. The origins of attachment theory: John Bowlby and Mary Ainsworth. Dev Psychol 1992;28:759.

27. Bowlby J. Attachment and loss: Retrospect and prospect. Am J Orthopsychiatry 1982;52:664-678.

28. Ainsworth MS, Bowlby J. An ethological approach to personality development. Am Psychol 1991;46:333.

29. Puig J, Englund MM, Simpson JA, Collins WA. Predicting adult physical illness from infant attachment: A prospective longitudinal study. Health Psychol 2013;32:409-417.

30. Nelson A. Unequal treatment: Confronting racial and ethnic disparities in health care. J Natl Med Assoc 2002;94:666-668.

31. Van Ryn M, Burke J. The effect of patient race and socioeconomic status on physicians' perceptions of patients. Soc Sci Med 2000;50:813-828.

32. Cooper-Patrick L, Gallo JJ, Gonzales JJ, et al. Race, gender, and partnership in the patient-physician relationship. JAMA 1999;282:583-589.

33. Piette JD, Heisler M, Krein S, Kerr EA. The role of patientphysician trust in moderating medication nonadherence due to cost pressures. Arch Intern Med 2005;165:1749-1755.

34. Piette JD, Richardson C, Valenstein M. Addressing the needs of patients with multiple chronic illnesses: The case of diabetes and depression. Am J Manag Care. 2004;10:152162.

35. Ciechanowski PS, Katon WJ, Russo JE. Depression and diabetes: Impact of depressive symptoms on adherence, function, and costs. Arch Intern Med 2000;160:3278-3285.

36. Ciechanowski PS, Katon WJ, Russo JE, Hirsch IB. The relationship of depressive symptoms to symptom reporting, self-care and glucose control in diabetes. Gen Hosp Psychiatry 2003;25:246-252.

37. Anderson RJ, Freedland KE, Clouse RE, Lustman PJ. The prevalence of comorbid depression in adults with diabetes: A meta-analysis. Diabetes Care 2001;24:1069-1078.

38. Gill JM, Mainous AG III. The role of provider continuity in preventing hospitalizations. Arch Fam Med 1998;7:352-357.

39. Gill JM, Mainous AG III, Nsereko M. The effect of continuity of care on emergency department use. Arch Fam Med 2000;9:333-338.

40. Mainous AG III, Gill JM. The importance of continuity of care in the likelihood of future hospitalization: Is site of care equivalent to a primary clinician? Am J Public Health 1998;88:1539-1541.

41. Mainous AG III, Baker R, Love MM, Gray DP, Gill JM. Continuity of care and trust in one's physician: Evidence 
from primary care in the United States and the United Kingdom. Fam Med 2001;33:22-27.

42. Starfield B. Primary Care: Concept, Evaluation, and Policy. New York: Oxford University Press; 1994.

43. Robert Wood Johnson Foundation. Health care's blind side: The overlooked connection between social needs and good health. Summary of findings from a survey of America's physicians. Available at: http://www.rwjf.org/content/ dam/farm/reports/surveys_and_polls/2011/rwjf71795. Accessed May 1, 2012.

44. Naylor MD, Brooten D, Campbell R, et al. Comprehensive discharge planning and home follow-up of hospitalized elders: A randomized clinical trial. JAMA 1999;281:613-620.
45. Bloom SL. The Sanctuary Model of organizational change for children's residential treatment. Therap Commun 2005;26: 61-78.

Address correspondence to: Dawn Mautner, MD, MS Department of Family and Community Medicine Thomas Jefferson University 1015 Walnut St, 401 Curtis Philadelphia, PA 19107

E-mail: dawn.mautner@jefferson.edu. 